\title{
Research Paper: \\ Comparing the Musculoskeletal Disorders of the Neck Between the Teachers of Physical Education and Other Majors in High Schools of Tehran City, Iran
}

\author{
Elham Rahimipour Najafabadi ${ }^{1}$ (D), Reza Rajabi ${ }^{*}$ (D), Mohammad Hossein Alizade ${ }^{3}$, Ali Mirabedi $^{3}$ (D)
}

1. MSc. Department of Health and Sport Medicin, Faculty of Physical Education and Sport Sciences, University of Tehran, Tehran, Iran.

2. Professor, Department of Health and Sport Medicin, Faculty of Physical Education and Sport Sciences, University of Tehran, Tehran, Iran.

3. PhD. of Sport Injury and Corrective Exercises, Alborz Campus, University of Tehran, Tehran, Iran.

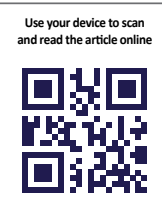

Citation Rahimipour Najafabadi E, Rajabi R, Alizade MH, Mirabedi A. Comparing the Musculoskeletal Disorders of the Neck Between the Teachers of Physical Education and Other Majors in the High Schools of Tehran City, Iran. Journal of Exercise Science and Medicine (JESM). 2019; 11(1):43-50. http://dx.doi.org/10.32598/JESM.11.1.5

http://dx.doi.org/10.32598/JESM.11.1.5

Keywords:

Musculoskeletal disorders, Physical education teacher, Teachers of other subjects, High school

\section{ABSTRACT}

Introduction: Musculoskeletal Disorders (MDs) largely contribute to occupational diseases in the workplace. Prevention from these disorders requires their evaluation in different occupations. This study aimed to compare the MDs of the neck between the teachers of Physical Education (PE) and those of the other majors in the high schools of Tehran City, Iran.

Methods: The study sample included 180 teachers of mathematics, $\mathrm{PE}$, and the religion and lifestyle in the high schools of Tehran (with the Mean \pm SD age of $42.11 \pm 6.65$ years, and the Mean $\pm S D$ weight of $72.28 \pm 12.98 \mathrm{~kg}$ ). The participants were selected from 19 districts of the Tehran Departments of Education using multistage cluster sampling. The standard Nordic questionnaire was administered to investigate MDs among the teachers. The obtained data were analyzed with the Chi-square test to compare the MDs of the neck between the three groups of teachers.

Results: A significant relationship was observed between the neck problems of the female $(P=0.016)$ and male $(P=0.017) P E$ teachers and the other teachers. Moreover, the neck problems were associated with the teaching experience $(P=0.024)$ and teaching major $(P=0.004)$.

Conclusion: Based on the results, it seems that regular exercise can reduce the developing risk of MDs in the neck. Thus, this study recommends the performance of regular exercise and the correction of job-related postures to all teachers.

\section{* Corresponding Author:}

Reza Rajabi, PhD.

Address: Professor, Department of Health and Sport Medicin, Faculty of Physical Education and Sport Sciences, University of Tehran, Tehran, Iran Tel: +98 (912) 1772997

E-mail: rrajabi@ut.ac.ir 


\section{Introduction}

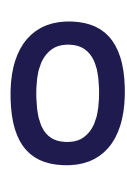

ccupational Musculoskeletal Disorders (MDs) are considered as the health-related problems in the workplaces of industrial and developing countries. These pains emerge because of the collective destruction of the tissues of the musculoskeletal system over the months and years of exposure to biomechanical and psychosocial stressors in the workplace [1].

Although psychosocial factors can cause these disorders, mechanical factors play the main role. The notable mechanical factors include limb posture, repeated movements in the joints, and the force applied during the work. The analysis of these factors and the employment of changes to the working conditions and workplaces considerably decrease the incidence of musculoskeletal pains [2].

Based on the available reports, the contribution of MDs to all occupational diseases is $31 \%$ in Finland (1994) and $44 \%$ in the US (1996) [1]. The demands of the job for the applied forces, repeated activities, or sustained posture in a long time impose unnatural stress on the human body. As the human body adapts automatically to reduce the physical stress, deviations occur in the natural posture of the body [3]. The sustained maintenance of the body in the unnatural postures and the repetition of movements cause postural deformities, discomfort, pain, and disability. The repetition of movements directs the body to the maintenance of unsymmetrical statuses [4], leading to the continuous use of a group of muscles and the neglecting of other muscles. This change will lead to a lack of balance in power, the length of muscles, and the flexibility of soft tissues. Gradually, these changes cause occupational disorders [5-7].

Most of these disorders are caused by mechanical factors that apply excessive tension or pressure to the soft tissues of the musculoskeletal system. These mechanical factors include performing movements outside the natural range-of-motion of the joint; applying continuous pressure or tension to the chords, muscles, and joints; and repeating abnormal physical postures. The range of these deformities depends on the intensity and the continuation of deviation from the normal body posture [8].

The vertebral column is of the most important parts. Over time, the human body changes based on the applied mechanical pressures, because it has a unique structure in every person and is affected by genetics and environmental conditions. If the applied pressures to the different movement planes of the vertebral column are asymmetrical, the incidence of undesirable changes and the pain will be higher [9]. The neck area in the vertebral column is exposed to several complications. When a limb or part of the body deviates from the normal and neutral status for a long time, the discomfort, pain, and MDs occur [10]. Based on the features of every job, one can identify these probable changes to some extent and prevent future pain by appropriate corrective exercises.

Based on the nature of the work and its features, there are different risk factors for developing MDs, in different jobs. Because of the repetition of some movements, such as sitting with the head bent forward for a long time, writing on the board (at the height above the shoulder and far from the shoulder joints), and scoring papers with the head down, teaching puts repeated pressure on muscles, bones, and the soft tissue in the neck. Thereby, this job causes an imbalance in muscles and exposes the person to complications that are the result of repeated and continuous postures and movements. Thus, the risk of postural disorders and pain is increased in teachers.

A review of the literature shows that numerous studies have been focused on the MDs of the neck and their relationship with different jobs. For example, Chiu and Lam (2007) examined the prevalence of neck pain among junior high school teachers in Hong Kong [11]. Chiu et al. (2006) studied full-time teachers in junior high schools [12]. Moreover, Erick and Smith [13] and Korkmaz and Kavlaku (2011) [14] have examined the MDs and risk factors in teachers and concluded that the neck pain is highly prevalent among teachers.

The present study tried to determine the MDs of the neck in Physical Education (PE) teachers who are expected to exercise regularly and have better physical fitness, based on the nature of their jobs. Also, they do not have the postures mentioned for other teachers, because they do not perform repetitive movements in special postures, such as writing on the board, sitting in a specific posture for a long time, and scoring the papers. Thus, we attempted to identify the role of the physical activity in the incidence of the MDs of the neck. We compared the MDs of the neck between the teachers of PE and teachers of the other majors. 


\section{Materials and Methods}

\section{Study design and participants}

This was an applied descriptive-comparative study. The statistical population comprised all the teachers of $P E$, mathematics, and religion and lifestyle, with at least five years of full-time teaching experience in the high schools of Tehran City, Iran. The study sample consisted of 180 teachers selected from 50 schools using the multistage cluster sampling method. Each of the three teaching majors included 60 participants with an equal number of men and women.

\section{Procedures}

This was an analytic epidemiological study with a cross-sectional comparative design and was performed in the high schools of Tehran using the standard Nordic questionnaire. Moreover, a form of personal and jobrelated information was completed by the participants. At the beginning of this form, written informed consent was obtained from the participants. To determine the validity and reliability of the job-related questionnaire, the opinions and experiences of the high school teachers and university professors were employed and a pilot study was conducted. The pilot study yielded the Cronbach alpha of 0.79 for the questionnaire. In this study, the Nordic questionnaire (the MDs of the neck) was administered, but only the information of some questions was used. The researcher distributed the questionnaires among the participants, visited all the schools after a week, and collected the questionnaires.

\section{Statistical analysis}

The collected data were analyzed in SPSS v. 15 using descriptive and inferential statistics at the significance level of $95 \%$ and the alpha value of 0.05 . The Chi-square test was run to compare the study groups in terms of the nature of data (non-parametric).

\section{Results}

In this work, teaching experience, teaching major, age, and gender were independent variables, and the neck

Table 1. Demographic characteristics of the study sample $(\mathrm{N}=180)$

\begin{tabular}{|c|c|c|c|c|}
\hline \multicolumn{3}{|c|}{ Variables } & \multirow{2}{*}{$\begin{array}{l}\text { Mean } \pm S D \\
40.73 \pm 7.33\end{array}$} & \multirow{2}{*}{$\begin{array}{c}\text { Range of Variance } \\
26\end{array}$} \\
\hline \multirow{6}{*}{$\begin{array}{l}\text { PE teachers } \\
\quad(n=60)\end{array}$} & \multirow{3}{*}{ Women } & Age $(y)$ & & \\
\hline & & Weight (kg) & $65 \pm 8.06$ & 33 \\
\hline & & Teaching experience (y) & $17.58 \pm 6.90$ & 25 \\
\hline & \multirow{3}{*}{ Men } & Age (y) & $43.46 \pm 8.46$ & 30 \\
\hline & & Weight (kg) & $78.46 \pm 11.10$ & 49 \\
\hline & & Teaching experience (y) & $20.53 \pm 7.91$ & 28 \\
\hline \multirow{6}{*}{$\begin{array}{l}\text { Mathematics } \\
\text { teachers } \\
(n=60)\end{array}$} & \multirow{3}{*}{ Women } & Age (y) & $40.3 \pm 5.74$ & 22 \\
\hline & & Weight (kg) & $66.66 \pm 9.30$ & 40 \\
\hline & & Teaching experience (year) & $17.26 \pm 5.01$ & 23 \\
\hline & \multirow{3}{*}{ Men } & Age (y) & $42.73 \pm 7.10$ & 28 \\
\hline & & Weight (kg) & $81.56 \pm 13.87$ & 55 \\
\hline & & Teaching experience (years) & $20.83 \pm 6.19$ & 22 \\
\hline \multirow{6}{*}{$\begin{array}{l}\text { Religion and life- } \\
\text { style teachers } \\
\quad(n=60)\end{array}$} & \multirow{3}{*}{ Women } & Age $(y)$ & $42.3 \pm 5.03$ & 20 \\
\hline & & Weight (kg) & $65.5 \pm 9.96$ & 51 \\
\hline & & Teaching experience (y) & $18.93 \pm 5.31$ & 22 \\
\hline & \multirow{3}{*}{ Men } & Age $(y)$ & $43.16 \pm 5.47$ & 20 \\
\hline & & Weight (kg) & $76.53 \pm 13.86$ & 44 \\
\hline & & Teaching experience (y) & $22.1 \pm 5.88$ & 25 \\
\hline
\end{tabular}

Exercise Science and Medicine 


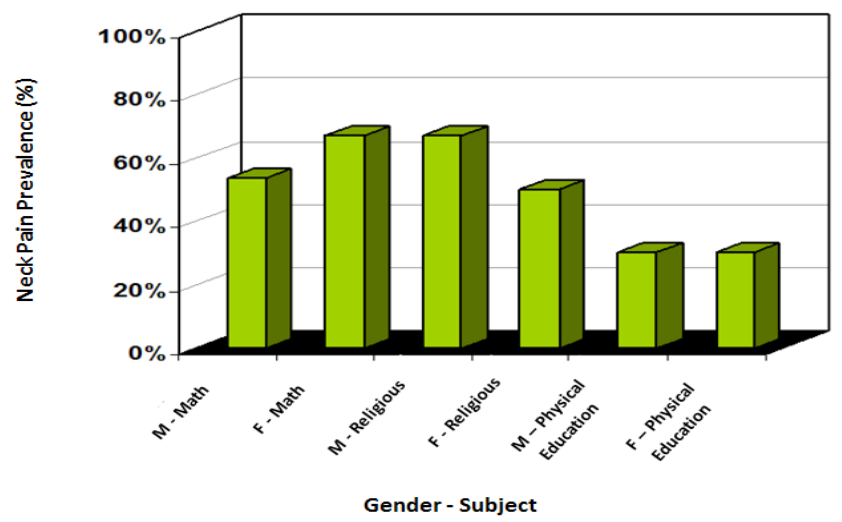

Exercise Science and Medicine

Figure 1. Prevalence and comparison of neck pain in the teachers of different majors by gender

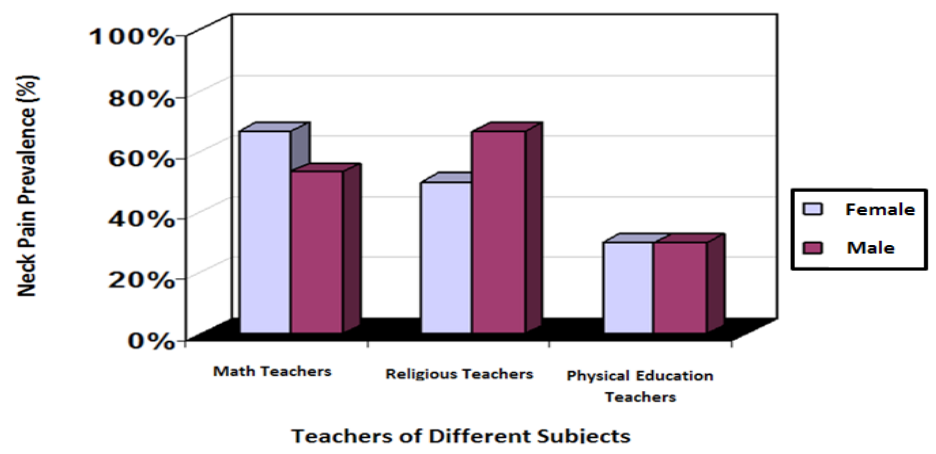

Figure 2. Prevalence and comparison of neck pain in the teachers of different majors

Exercise Science and Medicine

problem was the dependent variable. Table 1 reports the descriptive information of independent variables and the characteristics of the participants.

\section{Prevalence of neck pain}

Figure 1 displays the prevalence of neck pain by the teaching majors. The prevalence of neck pain in the teachers of mathematics, religion, and lifestyle, and PE was $60 \%$, $58 \%$, and $30 \%$, respectively. Results showed a significant difference in the neck pain between the teachers of $P E$ and those of the other majors $(P<0.002, P<0.05)$.

\section{Gender and neck pain}

In this study, the prevalence of neck pain among men and women was $50 \%$ and $48.8 \%$, respectively (Figure 2). Results indicated no significant relationship between gender and neck pain $(P=0.881)$. According to Figure 3 , the highest prevalence of neck pain belongs to the teach-

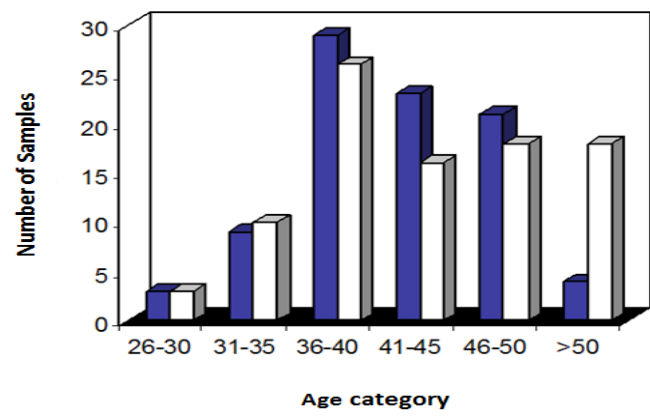

Figure 3. Frequency of neck pain in the different age groups of teachers by gender 


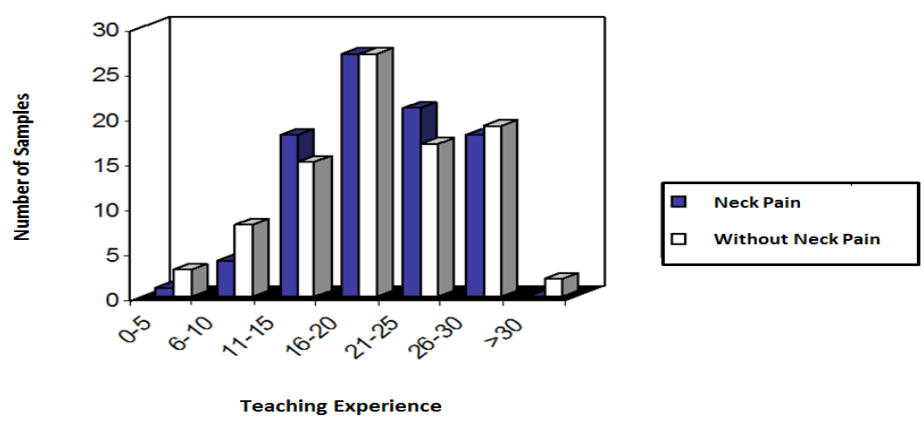

Figure 4. Frequency of neck pain in teachers with different work experiences by gender

Exercise Science and Medicine

ers with the age range of $41-45$ years, but no significant relationship was found between age and the prevalence of neck pain $(P=0.078)$.

\section{Teaching experience and neck pain}

According to Figure 4, the highest prevalence of neck pain belongs to the teachers with 21-25 years of teaching experience. Also, results showed a significant relationship between the teaching experience and neck pain $(P=0.024)$.

\section{Discussion}

In this study, the prevalence of neck pain was compared between the teachers of mathematics, religion, and lifestyle, and PE in the high schools of Tehran. Moreover, the prevalence of neck pain among the teachers with different age groups and gender, as well as the relationship between neck pain and teaching experience were evaluated.

Based on the results, the neck pain significantly differed between the women teaching PE and other majors $(P=0.017)$, and men teaching $P E$ and other majors $(P=0.016)$. Chiu and Lam (2007) examined the effect of physical activity on the neck pain of junior high school teachers and observed a significant relationship between the exercise (the neck muscle exercise) and pain reduction [11]. As a few studies have been conducted on this topic regarding teachers, the results of the present study cannot be directly compared with those of the other studies. Nevertheless, the studies of the positive effect of physical exercise on the reduction of neck disorders and pain can be cited to confirm our results. Numerous studies, including Takala (1994), Chiu (2005), Tsauo (2004), Kjellman (2002), and Waling (2002) [15-19] examined the effects of exercise programs on the reduction of disorders and pain in patients with neck pain, among computer users.
These findings can be explained considering the performance of regular exercise by the PE teachers. In the present study, a part of the sample was the high school PE teachers who mostly had a BS degree of PE, a 4-year regular exercise program (during the BS program), and a daily exercise plan for their job ( $90 \%$ of men and $66.6 \%$ of women). On the role of exercise in pain reduction, it can be stated that exercise stimulates the production of natural hormones that inhibit or decrease pain by increasing the pain threshold [20-23]. Also, exercise prepares the muscles and tissues of the neck and increases the capability of musculoskeletal tissues in this region against pressures. Besides, performing exercise reduces the accumulation of lactic acid in blood and delays fatigue that starts the pain [24]. Therefore, exercising could be a possible reason for the low prevalence of neck pain in $P E$ teachers, compared with the other teachers.

The occupational risk factors may also play a role in the incidence of neck pain and discomfort in the other teachers $[13,14,25]$. As the areas of neck and shoulders bear less weight than the lower limbs and the torso, most disorders in these regions may be caused by improper posture or the repetition and continuation of specific postures. The nature of the job of mathematics and religion and lifestyle teachers involves bending the head forward for reading and scoring papers in a long time, writing on the board (mostly in mathematics teachers), and sitting for a long time. Reading with the head bent forward can be a physical risk factor of neck pain [25-27]. The prevalence of neck pain is increased with the extent of the head being bent forward [20]. Thus, teachers are exposed to the high risk of the progression of occupational neck pain. Chiu et al. (2002) [28] studied the educational personnel of a university and concluded that bending the head forward for more than 15 minutes could affect neck pain. 


\section{Conclusion}

The results of the present study are consistent with those of Chiu et al. who reported a significant relationship between neck pain and teaching experience [11]. Furthermore, teachers with 21-25 years of teaching experience had the highest prevalence of neck pain.

Our results showed no significant relationship between gender and neck pain. Similarly, Lau et al. reported the same prevalence of neck pain for men and women (15\% and $17 \%$, respectively), in China [26]. On the other hand, considering that the pain threshold was increased with muscular power [29], Chiu et al. concluded that muscular isometric power was 1.2 to 1.7 times higher in men than in women. Therefore, the pain threshold must be lower in women than in men. In this regard, Chiu et al. reported similar results [11].

Despite the muscular power, the nature and culture of teaching in Iran could lead to the lack of a significant relationship between gender and neck pain. Most male teachers $(62.2 \%)$ have more than one job and most women work outside the home. Other reasons for the similarity of these disorders in men and women may be the mean weekly hours of teaching, which is higher in male teachers. The mean weekly hours of teaching is 34 and 23.5 for men and women, respectively.

Consequently, in the high schools of Tehran, teaching majors other than $\mathrm{PE}$ are related to neck pain considering their nature and posture. This shows the crucial effects of exercise on preventing the MDs in this large group. Therefore, the recommendation of exercise to the teachers and the consideration of the work-related posture may help to prevent and ameliorate the problem.

\section{Ethical Considerations}

\section{Compliance with ethical guidelines}

This study was approved by the Ethics Committee of Health and Sport Medicine, Physical Education and Sport Sciences of University of Tehran.

\section{Funding}

The present paper was extracted from the MA. thesis of Elham Rahimipour Najafabadi in the Faculty of Physical Education and Sport Sciences, University of Tehran, Tehran, Iran.

\section{Authors' contributions}

All authors were equally contributed in preparing this article.

\section{Conflict of interest}

The authors declared no conflict of interest.

\section{References}

[1] Choobineh AR. [Posture assessment methods in occupational ergonomics (Persian)]. Hamedan: Fanavaran; 2004.

[2] Choobineh A. [Development of an ergonomic carpet weaving workstation with emphasis on neutral working posture based on field survey and laboratory interventions[doctoral dissertation (Persian)]. Tehran: Tehran University of Medical Sciences; 2004.

[3] Dehghani Ghanateghestani A. Study of mycological infections in Kerman weavers (Persian)] [MSc. thesis]. Tehran: Tehran University of Medical Sciences; 1994.

[4] Sadeghian F, Javanmard M. [Assessment of musculoskeletal disorders in computer users and comparison with other office staff. (Persian)]. Presented at: First Congress on Prevention of Non-Infectious Diseases; 2002.

[5] Alizadeh MH, Bayat MR, Andam R. [Evaluation and comparison of hyper kyphosis in men volleyball and football players in Shahrood City with corrective-motor suggestions (Persian)]. Research in Sports Science. 2002; 1(1):89-99.

[6] Daneshmandi H, Alizadeh MH, Gharakhanlou R. Corrective exercises. Tehran: Jahad Daneshgahi Publicatin; 2002.

[7] Farahani A. Corrective exercises. Tehran: Payam-e Noor University Press; 2019

[8] Kendal FP, McCreary EK, Provance PG, Rodgers M, Romani W. Muscles: Testing and function with posture and pain: Testing and Testing and Function, with Posture and PainFunction, $5^{\text {th }}$ edition. Philadelphia: Wolters Kluwer Health; 2014

[9] Kapandji IA. [Kinesiology of tr lunk and spine joints (Persian)]. Tehran: Donyaye Honar; 2005.

[10] Kumar S. Theories of musculoskeletal injury causation. Ergonomics. 2001; 44(1):17-47. [DOI:10.1080/00140130120716] [PMID]

[11] Chiu TT, Lam PK. The prevalence of and risk factors for neck pain and upper limb pain among secondary school teachers in Hong Kong. Journal of Occupational Rehabilitation. 2007; 17(1):19-32 [DOI:10.1007/s10926-006-9046-z] [PMID]

[12] Chiu TW, Lau KT, Ho CW, Ma MC, Yeung TF, Cheung PM. A study on the prevalence and risk factors for neck pain in secondary school teachers. Public Health. 2006; 120:563-5.

[13] Erick PN, Smith DR. A systematic review of musculoskeletal disorders among school teachers. BMC Musculoskeletal Disorders. 2011; 12(1):260. [DOI:10.1186/1471-2474-12-260] [PMID] [PMCID] 
[14] Korkmaz NC, Cavlak U, Telci EA. Musculoskeletal pain, associated risk factors and coping strategies in school teachers. Scientific Research and Essays. 2011; 6(3):649-57. [DOI:10.5897/SRE10.1064]

[15] Takala EP. Static muscular load, an increasing hazard in modern information technology. Scandinavian Journal of Work, Environment \& Health. 2002; 28(4):211-3. [DOI:10.5271/sjweh.667] [PMID]

[16] Chiu TT, Lam TH, Hedley AJ. A randomized controlled trial on the efficacy of exercise for patients with chronic neck pain. Spine. 2005; 30(1):E1-E7. [DOI:10.1097/01.brs.0000149082.68262.b1]

[17] Tsauo JY, Lee HY, Hsu JH, Chen CY, Chen CJ. Physical exercise and health education for neck and shoulder complaints among sedentary workers. Journal of Rehabilitation Medicine. 2004; 36(6):253-7. [DOI:10.1080/16501970410029807] [PMID]

[18] Kjellman G, B Oberg. A randomized clinical trial comparing general exercise, McKenzie treatment and a control group in patients with neck pain. Journal of Rehabilitation Medicine. 2002; 34(4):18390. [DOI:10.1080/16501970213233] [PMID]

[19] Waling K, Järvholm B, Sundelin G. Effects of training on female trapezius myalgia: An intervention study with a 3-year followup period. Spine. 2002; 27(8):789-96. [DOI:10.1097/00007632200204150-00002] [PMID]

[20] Hayden JA, Van Tulder MW, Tomlinson G. Systematic review: Strategies for using exercise therapy to improve outcomes in chronic low back pain. Annals of Internal Medicine. 2005; 142(9):776-85. [DOI:10.7326/0003-4819-142-9-200505030-00014] [PMID]

[21] Lahad A, Malter AD, Berg AO, Deyo RA. The effectiveness of four interventions for the prevention of low back pain. Journal of the American Medical Association. 1994; 272(16):1286-91. [PMID]

[22] Mohseni-Bandpei MA. Chronic low back pain: A randomised controlled trial of spinal manipulation measuring pain, functional disability, lumbar movements and muscle endurance using surface electromyography. University of East Anglia; 2000. https://ethos. bl.uk/OrderDetails.do?uin=uk.bl.ethos. 365048

[23] Soukup MG, Lönn J, Glomsröd B, Larsen KBöS. Exercises and education as secondary prevention for recurrent low back pain. Physiotherapy Research International. 2001; 6(1):27-39. [DOI:10.1002/ pri.211] [PMID]

[24] Kenney WL, Wilmore JH, Costill DL. Physiology of sport and exercises [Z Moeini et al, Persian trans.]. $6^{\text {th }}$ edition. Tehran: Mobtakeran; 2002. http://opac.nlai.ir/opac-prod/bibliographic/543326

[25] Horng Y-S, Fu Hsieh S, Chi Wu H, Feng C-T, Lin M-C, et al. Workrelated musculoskeletal disorders of the workers in a child care institution. 2008; 36(1):15-21. [DOI:10.6315/2008.36(1)02]

[26] Lau E, Sham A, Wong K. The prevalence of and risk factors for neck pain in Hong Kong Chinese. Journal of Public Health. 1996; 18(4):396-9. [DOI:10.1093/oxfordjournals.pubmed.a024536] [PMID]

[27] Wahlstedt K, Norbäck D, Wieslander G, Skoglund L, Runeson R. Psychosocial and ergonomic factors, and their relation to musculoskeletal complaints in the Swedish workforce. International Journal of Occupational Safety and Ergonomics. 2010; 16(3):311-21. [DOI:1 $0.1080 / 10803548.2010 .11076848]$ [PMID]

[28] Chiu TTW, Ku WY, Lee MH, Sum WK, Wan MP, Wong CY, et al. A study on the prevalence of and risk factors for neck pain among university academic staff in Hong Kong. Journal of Occupational Rehabilitation. 2002; 12(2):77-91. [DOI:10.1023/A:1015008513575] [PMID]
[29] Torgén M, Swerup C. Individual factors and physical work load in relation to sensory thresholds in a middle-aged general population sample. European Journal of Applied Physiology. 2002; 86(5):418-27. [DOI:10.1007/s00421-001-0567-z] [PMID] 
This Page Intentionally Left Blank 